\title{
PERANAN KEPALA SEKOLAH DALAM MENINGKATKAN KEDISIPLINAN GURU DI SMA NEGERIRI 1 SAJOANGING
}

\author{
SRI RAHAYU \\ Dosen Pendidikan Ekonomi Universitas Pamulang \\ dosen02414@unpam.ac.id
}

\begin{abstract}
ABSTRAK
Penelitian ini merupakan penelitian ex post facto bertujuan Peranan Kepala Sekolah dalam Meningkatkan Kedisiplinan Guru di SMA Negeri 1 Sajoanging di Kabupaten Wajo. Yang menjadi populasi dalam penelitian adalah seluruh guru yang terdapat di SMA Negeri 1 Sajoanging Kabupaten Wajo. Dan dapaun sampel dalam penelitian berjumlah 28 orang. Dalam penelitian ini metode pengumpulan data dilakukan dengan menggunakan teknik observasi, membagikan angket kepada guru, dokumentasi, daan selanjutnya melakukan wawancara. Kemudian diolah dengan menggunakan penjelasan deskriptif kuantitatif. Berdasarkan analisis data diperoleh angka sebesar $94,64 \%$. Dimana angka dari 94,64\% berada pada interval $76 \%-100 \%$ atau berada dalam kategori berperan. Jadi Peranan Kepala Sekolah dalam Meningkatkan Kedisiplinan Guru di SMA Negeri 1 Sajoanging di Kabupaten Wajo di katakan "Berperan".

Kata Kunci : peranan kepala sekolah, kedisiplinan

\section{PENDAHULUAN}

Peningkatan kualitas pendidikan tidak hanya faktor yang bersifat makro tetapi juga ditentukan oleh dimensi mikro yang lebih oprasional atau bersentuhan langsung proses pembelajaran di sekolah. Disamping itu pola asuh orang tua di rumah juga berperan untuk peningkatkan perkembangan peserta didik.

Berbagai langkah awal demi terciptanya pendidikan yang berkualitas tinggi perlu kerjasama semua pihak, akan tetapi sejauh ini belum menampakkan hasil yang memuaskan. kegagalan itu

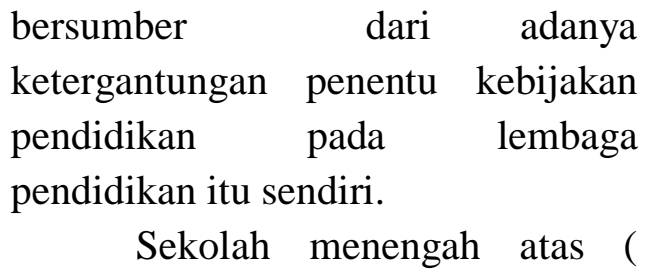
SMA) merupakan salah satu sekolah formal yang harus di tempuh terlebih dahulu kemudian melanjutkan ke perguruan tinggi negeri maupun swasta , maka perlu upaya yang maksimal dalam penyelenggaraan pendidikan pada sekolah menengah atas tersebut dan perlu diupayakan oleh guru dibawah pimpinan kepala sekolah sebagai salah satu elemen penentu kebijakan serta yang bertanggung jawab dalam usaha
\end{abstract}


meningkatkan kualitas pendidikan, diantaranya kedisiplinan guru yang harus datang tepat waktu serta mematuhi pertauran yang ada di lingkungan sekolah SMA Negeri 1 sajoanging karena kedisiplinan guru yang terdapat dilingkungan sekolah yang harus diperhatikan karena sebagai tenaga pendidik yang profesional mereka di tuntut untuk selalu memiliki sikap penuh keiklasan dalam mematuhi tata tertib yang ada di lingkungan SMA Negeri 1 sajoangin, menjadi seorang tenaga pendidik atau guru merupakan cerminan bagi siswa-siswi dalam dalam bersikap,

Selain peserta didik maka yang tidak kalah penting berperan dalam keberhasilan proses belajar mengajar adalah kepala sekolah, dalam menjalankan perannya itu maka kepala sekolah perlu melaksanakan peranan administrasi pendidikan yang pada dasarnya meliputi perencanaan, pelaksanaan, pengawasan dan kepeminpinan.

Keadaan sekarang sudah semakin berkembang maka kepala sekolah diharapkan dapat melaksanakan tugas dan perannya sebagai penyelenggara harus bertanggung jawab terhadap siswa beserta pegawai /tata usaha di sekolah dengan sebaik-baiknya,.

Pelaksanaan pembelajaran yang efisien tergantung dari seorang kepala sekolah dituntut agar selalu melaksanakan tanggung jawabnya beserta tugas-tugasnya agar setiap guru agar memiliki prilaku disiplin dalam proses penyusunan perencanaan, pelaksanaan evaluasi pengajaran.

Hasil survei awal yang dilakukan pada bulan JanuariFebruari 2013 menunjukkan adanya keadaan dimana kinerja guru mengalami menurunan secara dratis dan signifikan, hal ini dapat terlihat dari guru yang tidak sepenuhnya menjalan tugasnya, guru yang sering datang terlambat mengajar. Dan meninggalkan kelas pada saat proses pemebelajaran sedang berlangsung dimana sebagai seorang pendidik kesemuanya itu mesti ditaati sehingga mencerminkan seorang pendidik yang berhasil.

Berdasarkan kondisi di atas maka penulis tertarik untuk meneliti peranan kepala sekolah dalam meningkatkan kedisiplinan guru di SMA negeri 1 Sajoanging.

\section{METODE PENELITIAN}

Penelitian ini menggunakan pendekatan kualitatif deskriptif yaitu mengkaji Peranan Kepala Sekolah Dalam Meningkatkan Kedisiplinan Guru Di SMA Negeri 1 Sajoanging Di Kabupaten Wajo. Jadi penelitian ini hanya mengkaji satu variabel yaitu "Peranan Kepala Sekolah Dalam Meningkatkan Kedisiplinan Guru

\section{HASIL DAN PEMBAHASAN}

Hasil penelitian ini menujukkan bahwa guru yang ada di SMA Negeri1 Sajoanging sudah 
memiliki sikap dan tingkat kedisiplinan yang tinggi sesuai dengan amanah tugas dan tanggung jawab yang telah diberikan kepadanya.

\section{Bentuk Perhatian Kepala Sekolah Terhadap Pemberian Kesempatan Untuk Berkreasi Agar Terciptanya Iklim Sekolah yang Harmonis dan Demokratis SMA Negeri 1 Sajoanging}

Bentuk perhatian kepala sekolah terhadap pemberian kesempatan untuk berkreasi agar terciptanya iklim sekolah yang harmonis dan demokratis menurut bapak Aminuddin selaku kepala sekolah SMA Negeri 1 Sajoanging (Wawancara, Rabu Tanggal 27 Maret 2013) yakni dengan melakukan pemberian tugas sesuai kompetensi yang dimiliki setiap guru, mempercayakan penuh tugas tersebut kepada guru yang bersangkutan serta menganggapnya sebagai partner kerja bukan sebagai bawahan.

\section{Bentuk kebijakan-kebijakan}

kepala sekolah agar mendorong guru meningkatkkan sikap disiplin SMA Negeri 1 Sajoanging

Bentuk kebijakan-kebijakan kepala sekolah agar mendorong guru meningkatkkan sikap disiplin di SMA Negeri1 Sajoanging demokratis menurut bapak Aminuddin selaku kepala sekolah SMA Negeri 1 Sajoanging (Wawancara, Rabu Tanggal 27
Maret 2013) yakni dengan terlebih dahulu melaksanakan tugas kepala sekolah dengan penuh disiplin dengan berpijak pada sikap SIPAKATAU, SIPAKAINGE, SIPAKALEBBI (3S) yang artinya

Sipakatau adalah sifat yang tidak saling membeda-bedakan. Maksudnya, tidak membedakan antara satu dengan orang yang lainnya . Tidak ada perbedaan suku dan ras maupun agama,

Sipakinge adalah sifat dimana kita saling mengingatkan. Apabila ada diantara kita yang melakukan kesalahan apa salahnya agar sekiranya kita dapat saling mengingatka unntuk kebaikan sesama sesuai dengan ajaran agama

Sipakalebbi merupakan sifat yang saling menghormati antar sesama . Sebagai manusia yang beragama kita harus saling menghargai. Sifat saling menghormati dalam lingkungan bermasyarakat tentunya sangat berperan guna menciptakan kehidupan yang tentram aman dan sejahtera

\section{Bentuk perhatian kepala sekolah} terhadap guru yang memeiliki sikap disiplin yang tinggi

Bentuk sikap kepala sekolah terhadap guru yang memeiliki sikap disiplin yang tinggi di SMA Negeri1 Sajoanging menurut bapak Aminuddin, selaku kepala sekolah SMA Negeri 1 Sajoanging (Wawancara, Rabu Tanggal 30 Maret 2013) 


\begin{abstract}
"Guru yang memiliki sikap disiplin yang tinggi merupakan harapan pendidikan dan bangsa, menghargai prestasi guru dengan pujian perlu ada penghargaan atau reward seperti memberikan uang pembinaan/ucapan keberhasilan yang sudah dicapai guru serta tidak memberi nilai atau hukuman yang menjatuhkan guru."
\end{abstract}

\section{Hambatan Apa Saja Yang Dapat Menurunkan Kedisiplinan Guru di SMA Negeri 1 Sajoanging}

Hambatan Apa Saja Yang

Dapat menurunkan tingkat Kedisiplinan Guru Di SMA Negeri1 Sajoanging menurut bapak Aminuddin, selaku kepala sekolah SMA Negeri1 Sajoanging (Wawancara, Rabu Tanggal 27 Maret 2013). Mengatakan bahwa :

"Kepala sekolah pun mendapatkan hambatan dalam hal saran dan prasarana yang masih kurang di SMA Negeri 1 sajoanging karena melihat keberhasilan program pendidikan melalui proses pembelajaran sangat dipengaruhi oleh banyak faktor, salah satu di antaranya adalah tersedianya sarana dan prasarana pendidikan yang memadai disertai pemanfaatan dan pengelolaan secara optimal Kurangnya sarana dan prasarana yang di miliki SMA 1 Sajoanging antara lain listrik yang belum memenuhi kebutuhan yang diperlukan sekolah sehingga sekolah membutuhkan mesin generator ( mesin lampu) untuk memenuhi kebutuhan sekolah, kurangnya buku pelajaran / buku bacaan yang masih kurang di perpustakaan dan belum adanya Unit Kesehatan Sekolah (UKS), ini menjadi tugas saya selaku sebagai kepala sekolah yang tidak kalah penting untuk memenuhinya serta jarak rumah dengan sekolah yang relatif jauh dan adanya guru yang memiliki pekerjaan sampingan sehingga menghambat kedisiplinannya dalam mengajar di sekolah".

Hal-Hal Yang Dilakukan Kepala Sekolah Dalam Mengontrol Proses Belajar Mengajar Dikelas, Serta Bagaimana Menegur Guru Yang Melanggar Aturan di SMA Negeri1 Sajoanging.

Menurut bapak Aminuddin, selaku kepala sekolah SMA Negeri 1 Sajoanging mengatakan bahwa:

"Dengan mengontrol absen (daftar hadir) melaksanakan supervisi yang dilakukan kepada guru-guru diantaranya yaitu dengan memantau secara langsung proses pembelajaran yang dilakukan guru di dalam kelas, supervisi ini bertujuan agar guru mampu memperbaiki proses pembelajaran yang dilakukan dan jika ada yang melanggar aturan saya memanggil untuk berdiskusi mencari solusi yang 
baik." (Wawancara, Rabu

Tanggal 27 Maret 2013)

\section{Hal-hal yang dilakukan kepala sekolah untuk meningkatkan kedisiplinan guru}

Upaya-upaya yang dilakukan kepala sekolah untuk meningkatkan kedisiplinan guru Di SMA Negeri1 Sajoanging menurut bapak Aminuddin, selaku kepala sekolah SMA Negeril Sajoanging (Wawancara, Rabu Tanggal 27 Maret 2013). Mengatakan bahwa :

"Dengan melakukan pengawasan yang lebih intensif, serta memberikan penghargaan-penghargaan kepada guru yang berprestasi seperti memberikan uang pembinaan/ucapan

keberhasilan yang sudah dicapai guru dan berdisiplin sehingga dapat memotivasi kinerja guru. Kepala sekolah juga berperan sebagai pemimpin terbuka menerima saran atau masukan dari guru dan pegawai yang ada di sekolah dalam rangka peningkatan kinerja para guru dan pegawai."

Dari hasil wawancara kepala sekolah SMA Negeri 1 Sajoanging diperoleh data tentang langkah langkah atau tindakan yang dilakukan kepala SMA Negeri 1 Sajoanging dalam hal meningkatkan kedisiplinan guru sesuai peran kepala sekolah sebagai pemimpin, manejer, supervisor dan motivator. Adapun tindakan kepala sekolah dalam meningkatkan kedisiplinan guru SMA Negeri 1 Sajoanging Kabupaten Wajo.

Hasil analisis tanggapan responden tentang peranan kepala sekolah dalam meningkatkan kedisiplinan guru diperoleh hasil bahwa kepala sekolah sudah memberikan contoh keteladanan untuk meningkatkan kedisiplinan guru, sebanyak 100\% (28 responden) menyatakan YA dan $0 \%$ menyatakan kepala sekolah TIDAK memberikan contoh keteladanan untuk meningkatkan kedisiplinan guru, $100 \%$ (28 responden) menyatakan YA kepala sekolah terlebih dahulu memberikan contoh kedisiplinan dalam hal berpakaian dan $0 \%$ yang menyatakan kepala sekolah tidak memberikan contoh kedisiplinan dalam hal berpakaian. Selanjutnya tanggapan guru tentang sikap kepala sekolah dalam memberikan teguran dan saksi kepada guru yang tidak disiplin, diperoleh $92,86 \% \quad(26$ responden) menyatakan YA, dan $7,14 \%$ (2 responden) menyatakan TIDAK memberikan teguran dan saksi kepada guru yang tidak disiplin. Dari hasil ini diperoleh bahwa lebih banyak guru yang menyatakan YA atau setuju jika kepala sekolah sudah berperan dalam meningkatkan kedisiplinan guru di SMA Negeri Sajoanging. 
Dari segi kedisiplinan guru tercatat 14,29 responden yang menjawab ada guru yang terlamat masuk di dalam kelas pada waktu yang telah ditentukan ( Terlambat masuk). artinya lebih banyak guru yang ada di SMAN 1 Sajoanging melaksanakan kewajibannya sesuai dengan waktu yang ditentukan (tidak terlambat masuk). Tanggapan guru yang menyatakan Apakah selama ini bapak /ibu sudah dikatakan disiplin dalam pembelajaran yaitu sebanyak 96,43\% (27 responden) yang menyatakan sudah dikatakan disiplin dalam pembelajaran dan 3,57\% yang menyatakan TIDAK disiplin.dalam pembelajaran. Dan tanggapan responden tentang tugas dan tanggung jawab yang telah diberikan yaitu sebanyak 28 orang responden terdapat 27 orang yang menyatakan Ya atau sekitar 96,43 persen menyatakan bahwa tentang guru sudah dikatakan disiplin karena sudan menjalankan tugas yang diberikan kepadanya, kemudian ada 1 orang atau sekitar 3,57 responden yang tidak menjawab bahwa tentang guru sudah dikatakan disiplin sesuai dengan tugas dan tanggung jawab yang diberikan kepadanya.

Dari hasil analisis di atas , dapat disimpulkan bahwa kepala sekolah sangat berperan dalam meningkatan kedisiplinan guru di SMA Negeri 1 Sajoanging. Hal ini terlihat dari persentase tanggapan responden mengenai peranan kepala sekolah dan kedisiplinan guru yang secara keseluruhan persentasenya > $75 \%$.

\section{KEIMPULAN}

1. Peran Kepemimpinan Kepala Sekolah di Sma Negeri 1 Sajoanging

a. Kepala sekolah sebagai pemimpin yaitu kepala sekolah harus mempin guruguru yang ada di lingkungan SMA Negeri 1 Sajoanging supaya proses pembelajaran yang baik dapat telaksana sebaik mungkin. Dan sebagai seorang kepala sekolah harus dapat . menciptkan lingkungan yang kondusif, sehingga semua siswa dan guru betah berada di lingkugan sekolah

b. Kepala sekolah sebagai menajer sebagai seorang kepala sekolah harus dapat memimpin semua guru untuk mewujudkan tujuan yang diinginkan. Sebagai manajer kepala sekolah harus mampu mempergunakan seluruh sumber daya sekolah dalam maeningkatkan visi, misi dan memcapai tujuan sekolah.

c. Kepala sekolah sebagai supervisi tugas kepala sekolah adalah memberikan bimbingan, bantuan, pengawasan dan penilaian pada hambatan yang dihadapi semua guru khususnya yang berhubungan dengan proses 


pembelajaran sehingga
perbaikan program dan
kegiatan pendidikan dapat
menciptakan situasi belajar
mengajar.
Kepala sekolah berperan
sebagai motivator sebagai
seorang kepala sekolah harus
mampu memberikan motivasi
bagi guru, sehingga dapat
meningkatkan kinerja dan
prestasinya

2. Dalam meningkatkan kedisiplinan guru kepala sekolah memiliki kendala dalam hal peralatan dan perlengkapan sekolah yang masih kurang sebagai faktor pendukung proses pembelajaran di sekolah serperti masih kurangnya persediaan buku pelajaran di perpustakaan, dalam upaya peningkatan kedisiplinan para guru di SMA Negeri1 Sajoanging.

3. Upaya-upaya yang dapat dilakukan kepala sekolah agar kedisiplinan guru dapat meningkat yaitu dengan memberikan rewerd dan penghargaan kepada guru yang berprestasi dan berdisiplin sehingga dapat memotivasi kinerja guru kemudian selain itu juga di haruskan terbuka dalam menerima kritikan dan masukan dari guru.

\section{REFERENSI}

Arikunto, Suharsimin. (1996). Prosedur Penelitian Suatu Pendekatan Praktek. Jakarta : Rineka Cipta

Atmosudirdjo. (1997). Beberapa Pandangan Umum Tentang Pengambilan Keputusan (Decision Making), Jakarta : Ghalia

Dwiyanto, Agus, (2002). Reformasi Birokrasi Publik di Indonesia, Yogyakarta : Galang Printika.

Efferin, Sujoko; Hadi Darmadji, Stevanus; Tan, Yuliawati. (2008). Metode penelitian akuntansi : Mengungkap Fenomena Dengan Pendekatan Kuantitatif Dan Kualitatif. yogyakarta : Graha ilmu.

Getol, gunadi (2012). Management Miracle Series Accepted Leader, PT.Elex Media Komputindo, Jakarta

Ilyas, (2001). Kinerja, Teori Penilaian dan Penelitian, Jakarta: Universitas Indonesia

Jackson, J.H, Morgan,CP, dan Paolillo,J, (1978). Organization Theory, A Macro Perspective for management, Prentice-Hall, U.S.A.

Lako, Andreas. (2004). Kepemimpinan dan Kinerja Organisasi, ISU, Teori dan Solusi. Yogyakarta: Amarah Books.

Maryuningtyas, Indah, (2005).

Pengaruh Motivasi Kerja Terhadap Kinerja Pelayanan 
kepada Masyarakat, (Studi tentang Pelayanan Kartu Pencari Kerja di Kantor Suku Dinas Tenaga Kerja dan Transmigrasi Kotamadya Jakarta Selatan Provinsi DKI Jakarta) Tesis, Bandung; Program Pascasarjana Unpad

Prawirosentono, (1999). Sumber Daya Manusia, Kesempatan Kerja dan Pembangunan Ekonomi, Jakarta: LPFE-UI.

Lako, Andreas. (2004). Kepemimpinan dan Kinerja Organisasi. Yogyakarta : Amara Books.

Sadeli. (1996). Kepemimpinan Dan

Kerja Sama. Ikip ujung pandang Sugiyono, (2006). Metode Penelitian

Bisnis, bandung : CV alfabeta

Sugiyono. (2007). Metode Penelitian

Administrasi. Bandung,

Alfabeta.

Siagian Sondang P. (2004).

Manajemen Abad Dua Satu

Jakarta: Bumi Aksara.

Siagian, Sondang P. (2001).

Manajemen Sumber Daya

Manusia. Jakarta : PT. Bumi

Aksara.

Siagian, Sondang P. (2002). Kiat

Peningkatan Prduktivitas Kerja.

Jakarta : Rineka Cipta.

Siagian, Sondang P. (1997). Filsafat

Administrasi. Jakarta PT. Gunung Agung

Syamsi, Ibnu. (1994). Pokok-Pokok

Organisasi dan Manajemen.

Jakarta :Rineka Cipta.
Terry. (1996). Perilaku Organisasi, Konsep Dasar, dan Aplikasinya. Jakarta : Raja Gravindo Persada.

Thoha, Miftah. (1999). Kepemimpinan Dalam Manajemen Suatu Pendekatan Perilaku. Jakarta : PT.Raja Grafindo Persada.

Wursanto, (2005). Dasar-dasar Ilmu Organisasi, Yogyakarta : Andi. 